\title{
Changes in Renal Function One Year after Radical Nephrectomy for Cancer Compared to Kidney Donation
}

\author{
Cristiano Trindade de Andrade ${ }^{1}$, Wagner Eduardo Matheus ${ }^{1}$, Ubirajara Ferreira ${ }^{1}$, Marilda Mazzali ${ }^{2,3 *}$, and Marcelo Lopes de \\ Lima $^{1,3}$
}

${ }^{1}$ Department of Surgery, University of Campinas, Campinas, Brazil

${ }^{2}$ Department of Medical Sciences, University of Campinas, Campinas, Brazil

${ }^{3}$ Laboratory of Investigation in Transplant (LINT), School of Medical Sciences, University of Campinas, Campinas, Brazil

*Corresponding author: Marilda Mazzali, Laboratory of Investigation in Transplant/Renal Transplant Unit, Department of Medicine, School of Medical Sciences, University of Campinas Rua Tessália Vieira de Camargo, 126, Cidade Universitária Zeferino Vaz, 13.083-970, Campinas, São Paulo, Brazil, Fax: (55-19) 35218204; E-mail: marildamazzali@gmail.com; mmazzali@fcm.unicamp.br

Received: 01 Nov, 2019 | Accepted: 19 Nov, 2019 | Published: 22 Nov, 2019

Citation: de Andrade CT, Matheus WE, Ferreira U, Mazzali M, de Lima ML (2019) Changes in Renal Function One Year after Radical Nephrectomy for Cancer Compared to Kidney Donation. Int J Nephrol Kidney Fail 5(4): dx.doi.org/10.16966/2380-5498.185

Copyright: (c) 2019 de Andrade CT, et al. This is an open-access article distributed under the terms of the Creative Commons Attribution License, which permits unrestricted use, distribution, and reproduction in any medium, provided the original author and source are credited.

\begin{abstract}
Purpose: Adaptive changes to acute reduction in renal mass after radical nephrectomy can cause Chronic Kidney Disease (CKD) more frequently in patients with renal cancer compared to kidney donors. The aim of this study was to compare changes in Estimated Glomerular Filtration Rate (eGFR) 1 -year after radical nephrectomy for cancer vs kidney donation and to identify risk factors for CKD.

Methods: Medical records from 79 patients submitted to nephrectomy from January 2008 to September 2013, divided into 2 groups, according to the indication of nephrectomy: kidney donor $(n=39)$ and renal tumor $(n=40)$ were analyzed for demographic data, presence of comorbidities, tumor size and eGFR by the Chronic Kidney Disease-Epidemiology (CKD-EPI) formula, at baseline and 12 months post nephrectomy.

Results: In the donor group, there was a reduction of 31.3\% in e-GFR within 1-year, and 25.6\% were classified as CKD-3 (eGFR $<60 \mathrm{ml} / \mathrm{min} / 1.73 \mathrm{~m} \mathrm{~m}^{2}$ ). Risk factors were age $>50$ years old and overweight $(p=0.0268)$. In the tumor group, reduction in e-GFR was of $18.8 \%$, but $57.5 \%$ of patients became CKD-3. The only risk factor was the presence of comorbidities $(p=0.0354)$. Analysis of tumor size showed a significant reduction in e-GFR for tumors $\leq 7 \mathrm{~cm}$, while for tumors $>15 \mathrm{~cm}$ eGFR remained similar to baseline levels.

Conclusion: Risk factors for CKD, 1-year after radical nephrectomy, were the presence of hypertension or diabetes in patients with renal cancer, and overweight and age $>50$ years old for kidney donors. The increased loss of eGFR for tumors $<7 \mathrm{~cm}$ suggest that partial nephrectomy should be considered when possible.
\end{abstract}

Keywords: Radical nephrectomy; Kidney donation; Renal function; Renal cell carcinoma

\section{Introduction}

The reported long-term safety of living kidney donation seems a paradoxical situation when compared to the increased risk for chronic kidney disease (CKD) after radical nephrectomy in patients with renal cancer [1,2]. Despite a reported loss of 30\% in glomerular filtration rate following unilateral nephrectomy, only 0.3 to $0.5 \%$ of kidney donors progressed to end stage CKD with need for renal replacement therapy $[1,3]$. However, for patients submitted to radical nephrectomy for cancer, rates of CKD are higher, around 40 to $75 \%$ to stage 3 and 1 to $2 \%$ of end stage CKD [4-6]. These differences can be related to patient characteristics and associated risk factors, such as age at the time of nephrectomy and the presence of comorbidities like hypertension and diabetes $[7,8]$. Renal function at the time of surgery also can impact progression of renal disease, with an increased risk for CKD stage 3 in patients with an initial eGFR between 60 to $89 \mathrm{ml} /$ $\min / 1.73 \mathrm{~m}^{2}[9]$.
In recent years, preservation of renal mass and function has been considered as important as the oncologic quality of the procedure, with a tendency to perform partial nephrectomies or ablative procedures when possible [7]. However, for large tumors, the preservation of renal mass remains a problem. The aim of this study was to compare changes in eGFR 1-year after radical nephrectomy for cancer vs. kidney donation and to identify risk factors for CKD.

\section{Material and Methods}

\section{Retrospective study from a single center}

Data was collected from medical records and Renal Transplant Unit database. The Ethics Committee from University of Campinas approved the study protocol.

\section{Inclusion criteria}

Patients submitted to unilateral nephrectomy from January/2008 
to September/2013 for tumor resection or renal donations were older than 18 years old and with a follow up after nephrectomy longer than 12 months.

\section{Exclusion criteria}

Previous CKD, defined as eGFR $<60 \mathrm{ml} / \mathrm{min} / 1.73 \mathrm{~m}^{2}$; death or loss of follow-up within 12 months after surgery; presence of metastasis at the time of diagnosis; histological diagnosis of sarcoma or urothelial carcinoma and presence of a synchronous tumor in the contralateral kidney.

\section{Collected data}

Included gender, age at nephrectomy, presence of comorbidities (hypertension and/or diabetes), serum creatinine and tumor size. eGFR was calculated by the Chronic Kidney Disease Epidemiology (CKD-EPI) equation [10], using serum creatinine at two time points: baseline (pre-operatively) and after 12 months of follow up.

For analysis, patients were divided into 2 groups: donor (nephrectomy for renal donation) and tumor (radical nephrectomy for concert assess the impact of nephrectomy on renal function. The groups were subdivided into according to postoperative eGFR: CKD group (eGFR $<60 \mathrm{ml} / \mathrm{min} / 1.73 \mathrm{~m}^{2}$ ) or control group (eGFR $\geq 60 \mathrm{ml} /$ $\min / 1.73 \mathrm{~m}^{2}$ ), according to CKD classification of National Kidney Foundation [11].

\section{Statistical analysis}

Numerical data was presented as mean \pm standard deviation. MannWhitney test was used to compare means between the two groups and Wilcoxon test for paired data was used to compare 2 time points of the same group. Fisher's exact test was used for qualitative and Pearson's correlation for numerical variables. Multiple linear regression was used to identify risk factors. Statistical significance was considered if $\mathrm{p}<0.05$.

\section{Results}

From January 2008 to September 2013, 130 consecutive unilateral nephrectomies were performed at Clinics Hospital of University of Campinas. For analysis, patients were divided according to the indications for surgery in the donor group $(n=60$, unilateral nephrectomy for kidney donation) and the tumor group ( $\mathrm{n}=62$, radical nephrectomy for kidney cancer). After applying the inclusion and exclusion criteria, 39 patients from the donor group and 40 patients from the tumor group were selected (Figure 1).

Patients in the tumor group were older, with a lower pre operatory eGFR and presented with a higher incidence of comorbidities, such as systemic hypertension or diabetes compared to the donor group (Table 1).

Analysis of changes in glomerular filtration rate showed that both groups presented a significant reduction in eGFR at the end of the first year, with the higher eGFR for the donor group $(29.9 \pm 11.2 \mathrm{ml} /$ $\mathrm{min} / 1.73 \mathrm{~m}^{2}$ body surface versus $14.2 \pm 18.3 \mathrm{ml} / \mathrm{min} / 1.73 \mathrm{~m}^{2}$ body surface, donor $v s$ tumor, $\mathrm{p}<0.05$ ) (Figure 2), but this reduction is less significant when compared to the tumor group, whereas eGFR in the donor group is higher after one year. When we analyzed the percentage of patients with $\mathrm{CKD}$, defined as glomerular filtration rate (GFR) lower than $60 \mathrm{ml} / \mathrm{min} / 1.73 \mathrm{~m}^{2}$ for greater than 3 months, the tumor group had a higher incidence of CKD (57.5\% versus $25.2 \%$, $\mathrm{p}$ $<0.05)$. In order to identify possible risk factors for the unfavorable outcome, each group was divided into 2 subgroups, with 1-year eGFR $<60 \mathrm{ml} / \mathrm{min} / 1.73 \mathrm{~m}^{2}$ or e-GFR $\geq 60 \mathrm{ml} / \mathrm{min} / 1.73 \mathrm{~m}^{2}$ body surface.

In the renal donor group, the multivariate analysis showed that the increase in Body mass index (BMI) $(\mathrm{p}=0,015)$ and donors older than 50 years old $(\mathrm{p}=0,021)$ were associated with a lower postoperative eGFR and had a higher chance to progress to CKD within the first year after surgery (Table 2).

In the tumor group, in univariate analysis, risk for final eGFR $<60$ $\mathrm{ml} / \mathrm{min} / 1.73 \mathrm{~m}^{2}$ body surface were the presence of comorbidities like hypertension or diabetes $(\mathrm{p}=0.0034)$ and patients older than 60 years at the time of surgery $(\mathrm{p}=0.0235)$. However, after multivariate analysis, only comorbidities of hypertension and/or diabetes were risk factors $(\mathrm{p}=0.0354)$, with a 7 -times increase in the chance for eGFR lower than $60 \mathrm{ml} / \mathrm{min} / 1.73 \mathrm{~m}^{2}$ body surface one year after surgery (Table 2 ).

In this series, the mean size of tumors in patients submitted to nephrectomy was of $9.77 \pm 4,5 \mathrm{~cm}$. When nephrectomy was performed for tumors $\geq 15 \mathrm{~cm}$ there was no variation in eGFR $(58,5 \pm 19,1 v s$. $57.4 \pm 18,6 \mathrm{ml} / \mathrm{min} / 1.73 \mathrm{~m}^{2}$ body surface, $\mathrm{p}=\mathrm{ns}$ ); whereas for tumors smaller than $7 \mathrm{~cm}$ we observed a higher reduction in eGFR within the first year after transplant $(80.8 \pm 18.8 v s .57 .5 \pm 15.9 \mathrm{ml} / \mathrm{min} / 1.73$

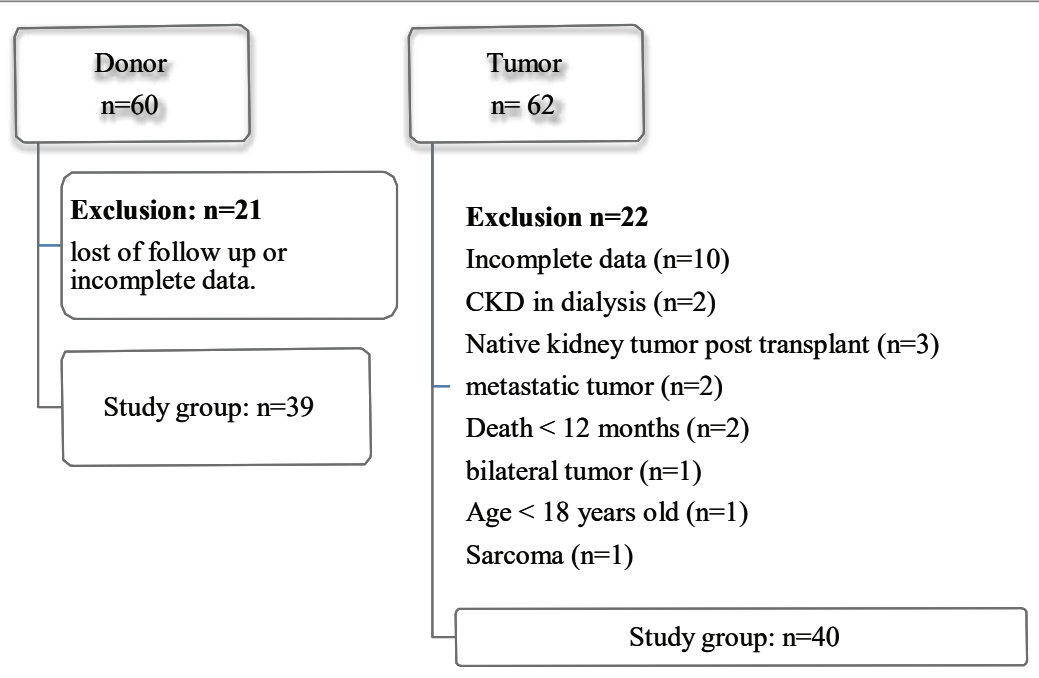

Figure 1: Glycemic status among CKD patients with (a) and without (b) history of DM (N=328). 
Table 1: Demographic characteristics of patients according to study groups.

\begin{tabular}{|c|c|c|c|}
\hline & Donor group & Tumor group & p \\
\hline Number of patients & 39 & 40 & - \\
\hline Age (years) & $43.1 \pm 8.0$ & $64.1 \pm 8.5$ & $<.0001$ \\
\hline Gender (male:female) & $16: 23$ & $18: 22$ & 0,1431 \\
\hline Hypertension-n (\%) & 0 & $24(60)$ & $<.0001$ \\
\hline Diabetes & 0 & $12(30)$ & $<.0001$ \\
\hline Tumor size $(\mathrm{cm})$ & na & $9.77 \pm 4.5$ & - \\
\hline \multicolumn{4}{|l|}{ eGFR $\left(\mathrm{ml} / \mathrm{min} / 1.73 \mathrm{~m}^{2}\right)$} \\
\hline pre-operative & $95.5 \pm 15.2$ & $9.77 \pm 4.5$ & $<.0001$ \\
\hline 1-year follow up & $65.6 \pm 13.0$ & $61.1 \pm 18.4$ & 0,0857 \\
\hline $\begin{array}{l}\text { Variation of eGFR }(\mathrm{ml} / \\
\left.\mathrm{min} / 1.73 \mathrm{~m}^{2}\right)\end{array}$ & $29.9 \pm 11.2$ & $14.2 \pm 18.3$ & $<.0001$ \\
\hline
\end{tabular}

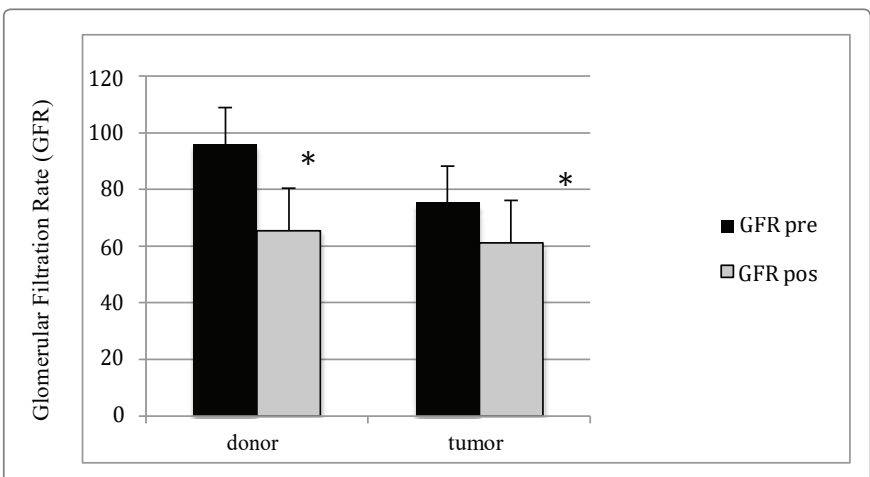

$* p=0.0001$

Figure 2: Variations in eGFR one-year after unilateral nephrectomy according to study groups.

$\mathrm{m}^{2}$, body surface $\left.\mathrm{p}=0,0648\right)$, suggesting that tumor size influences the evolution of eGFR (Figure 3).

\section{Discussion}

In this study we observed differences in the risks for progression to $\mathrm{CKD}$ after nephrectomy when comparing kidney donation or radical nephrectomy for tumors. About a quarter of the kidney donors progressed to eGFR $<60 \mathrm{ml} / \mathrm{min} / 1.73 \mathrm{~m}^{2}$ body surface, a slightly higher incidence than previously reported [1]. In contrast, more than a half of the patients from the tumor group progressed to eGFR lower than $60 \mathrm{ml} / \mathrm{min} / 1.73 \mathrm{~m}^{2}$ body surface, similar to previous reports $[6-8,12]$.

After a radical nephrectomy, the remnant kidney has to adapt to the abrupt loss of renal mass and eGFR reduction. The adaptive process can be slow, lasting as long as 5 years, but progression to end stage CKD is rare, lower than 1\%. Ibrahim HN, et al. [1] followed 3698 kidney donors over 30 years, and observed that despite an incidence of $14.5 \%$ of stage $3 \mathrm{CKD}$, only $11(0.3 \%)$ donors progressed to end-stage kidney disease with the need for dialysis or transplant, around 22.5 \pm 10.4 years after donation [1]. In radical nephrectomies for tumor, Huang WC, et al. [6] showed an incidence of $65 \%$ of eGFR $<60 \mathrm{ml} /$ $\min / 1.73 \mathrm{~m}^{2}$ body surface three years after surgery. While in the study of Malcolm JB, et al. the incidence reported was of $44.7 \%$ in a 5 -year follow up [7].

Preoperative eGFR lower than $90 \mathrm{ml} / \mathrm{min} / 1.73 \mathrm{~m}^{2}$ body surface has been reported in several series as an important risk factor for progression to postoperative $\mathrm{CKD}$ [9,13-15]. The initial filtration rate

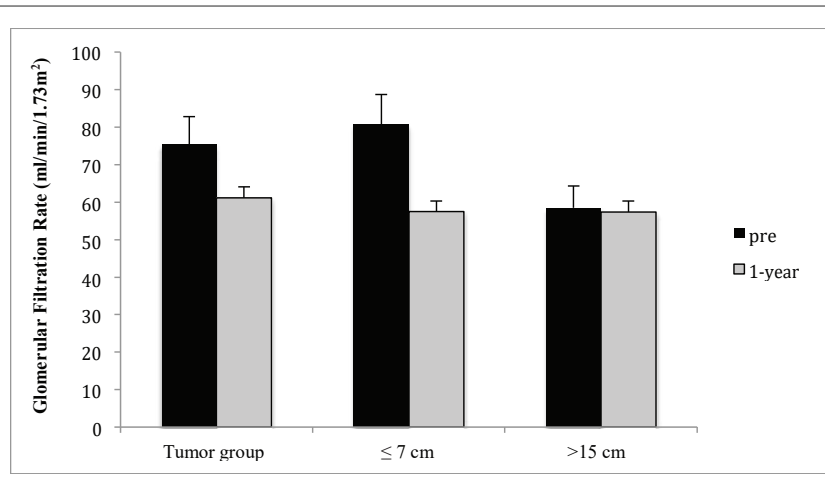

Figure 3: Influence of tumor size on adaptation of glomerular filtration rate one-year after nephrectomy.

in the tumor group was around $80 \mathrm{ml} / \mathrm{min} / 1.73 \mathrm{~m}^{2}$, which contributed to a lower eGFR 1-year after nephrectomy.

The differences in progression to CKD from donor and tumor groups could be attributed to the patient's characteristics. Kidney donors are usually younger with initial renal function higher than 80 $\mathrm{ml} / \mathrm{min} / 1.73 \mathrm{~m}^{2}$ and don't have comorbidities such as hypertension or diabetes.

Patients with tumors are older with an initial lower eGFR and usually have associated comorbidities like hypertension and diabetes that were isolated risk factors for progression to CKD in this group, similar to previous reports $[2,13]$. For donors, the presence of hypertension and diabetes are contra indications to donation. These variables were not analyzed. However, the higher body mass index was a risk factor for lower eGFR in the donor group. Previous studies showed an association of higher BMI and lower eGFR after surgery [7,16,17]. Bello RC, et al. reported that the frequency of systemic hypertension increased by $10 \%$ for every 1 unit of increase in BMI, which probably explains the worse outcome in this group of patients [16]. Also, increase in BMI is an initial trigger for other metabolic syndrome abnormalities.

The influence of age at nephrectomy in the progression to CKD is controversial, but should be considered when analyzing the risks of surgery. In this study, for donors older than 50 years we observed a trend towards lower one-year eGFR. Similar data was observed by Dols LF, et al. who followed 539 donors for 5.5 years and observed that $80 \%$ of the patients older than 60 years had a final eGFR $<60$ $\mathrm{ml} / \mathrm{min} / 1.73 \mathrm{~m}^{2}$ body surface compared to $31 \%$ of patients younger than 60 years old [14]. However, despite of the higher incidence of CKD stage 3, none of the patients progressed to stages 4 or 5 [14]. In contrast, in the tumor group, age $>60$ years old in this series was a risk factor only by univariate analysis.

One should consider that radical nephrectomy in patients with renal cancer and absence of comorbidities could have a similar impact than in healthy donors. Timsit MO, et al. analyzed a group of patients with radical nephrectomy due to cancer with few comorbidities and compared to the kidney donors paired for age and length of follow up. They observed a reduction of $30 \%$ in eGFR in both groups, suggesting that the presence of comorbidities at the time of surgery has a negative impact on long term renal function [18].

The influence of tumor size in adaptation of GFR was analyzed. In patients with tumors larger than $15 \mathrm{~cm}$, we did not observe significant changes in GFR within 1-year after the procedure, suggesting that the 
Table 2: Risk factors for 1-year eGFR $<60 \mathrm{ml} / \mathrm{min} / 1.73 \mathrm{~m}^{2}$ body surface, according to study groups.

\begin{tabular}{|c|c|c|c|c|c|c|}
\hline & Univariate & & $\mathbf{p}$ & multivariate & & $p$ \\
\hline \multicolumn{7}{|c|}{ Donor group } \\
\hline Age $>50$ years & 13 & $(2.1-71.4)$ & 0,5574 & 25,6 & $(1.6-400)$ & 0,0209 \\
\hline BMI & 2 & $(1.4-3.7)$ & 0,468 & 2,232 & $(1.2-4.3)$ & 0,0145 \\
\hline \multicolumn{7}{|c|}{ Tumor group } \\
\hline Age $>60$ years & 5,2 & $(1.3-20.4)$ & 0,0235 & 2,2 & $(0.4-13.0)$ & 0,3866 \\
\hline eGFR 60 to 89 & 2,6 & $(0.7-9.4)$ & 0,1991 & 3,1 & $(0.6-14.9)$ & 0,1599 \\
\hline Comorbidities & 8,7 & $(2.0-38.5)$ & 0,0034 & 7 & $(1.1-43.3)$ & 0,0354 \\
\hline
\end{tabular}

diffuse tumor infiltration spares only a small amount of healthy renal parenchyma. These kidneys behave as a functionally excluded kidney. For tumors smaller than $7 \mathrm{~cm}$ radical nephrectomy was associated with a higher variation in GFR, similar to that observed in the donor group, suggesting that healthy renal tissue should be preserved. A previous study from Ohno $\mathrm{Y}$, et al. showed similar changes in GFR, comparing tumors smaller or larger than $7 \mathrm{~cm}$, which suggests that partial nephrectomy should be indicated for tumors smaller than $7 \mathrm{~cm}$ if technically possible [19].

The limitations of the study are the retrospective design and the small number of patients evaluated. However, this series contributes clinically and can serve as the basis for a nomogram to estimate the impact of nephrectomy on the GFR, considering the various risks factors. Preservation of renal function is a part of good surgical programming.

\section{Conclusion}

In this series, despite a reduction of $30 \mathrm{ml} / \mathrm{min} / 1.73 \mathrm{~m}^{2}$ body surfaces one year after nephrectomy, only a quarter of donors progressed to CKD stage 3, with an increased risk for overweight donors. In the tumor group, more than a half of patients progressed to CKD-3 and independent risk factors resulted in a worse prognosis because of comorbidities like hypertension or diabetes.

Tumor size influenced postoperative GFR in this study. Nephrectomies for tumors smaller than $7 \mathrm{~cm}$ had a greater variation of GFR, whereas patients with tumors larger than $15 \mathrm{~cm}$ showed no significant change in GFR after the procedure.

\section{Author's Contribution}

CT Andrade: data collection, manuscript writing, WE Matheus: tumor group database, U Ferreira: tumor group database, M Mazzali: project development, manuscript correction, ML Lima: project development, manuscript writing.

\section{Acknowledgment}

We are thankful to the Urology-Oncology group of University of Campinas, especially to Prof. Ubirajara Ferreira and Dr. Wagner Eduardo Matheus for facilitating the access to medical records of patients from the tumor group.

We are thankful to Mariana Bertoncelli Tanaka to help us with data collection.

\section{References}

1. Ibrahim HN, Foley R, Tan L, Rogers T, Bailey RF, et al. (2009) Longterm consequences of kidney donation. N Engl J Med 360: 459-469.

2. Takeshita H, Yokoyama M, Fujii Y, Chiba K, Ishioka J, et al. (2012) Impact of renal function on cardiovascular events in patients undergoing radical nephrectomy for renal cancer. Int J Urol 19: 722728.

3. Muzaale AD, Massie AB, Wang MC, Montgomery RA, McBride MA, et al. (2014) Risk of end-stage renal disease following live kidney donation. JAMA 311: 579-586.

4. Shimada S, Saito H, Kawasaki Y, Yamashita S, Adachi H, et al. (2017) Clinical predictors of the estimated glomerular filtration rate 1 year after radical nephrectomy in Japanese patients. Investig Clin Urol 58: 228-234.

5. Yokoyama M, Fujii Y, limura Y, Saito K, Koga F, et al. (2011) Longitudinal change in renal function after radical nephrectomy in Japanese patients with renal cortical tumors. J Urol 185: 2066-2071.

6. Huang WC, Levey AS, Serio AM, Snyder M, Vickers AJ, et al. (2006) Chronic kidney disease after nephrectomy in patients with renal cortical tumours: a retrospective cohort study. Lancet Oncol 7: 735740.

7. Malcolm JB, Bagrodia A, Derweesh IH, Mehrazin R, Diblasio CJ, et al. (2009) Comparison of rates and risk factors for developing chronic renal insufficiency, proteinuria and metabolic acidosis after radical or partial nephrectomy. BJU Int 104: 476-481.

8. Barlow LJ, Korets R, Laudano M, Benson M, McKiernan J (2010) Predicting renal functional outcomes after surgery for renal cortical tumours: a multifactorial analysis. BJU Int 106: 489-492.

9. Hew MN, Opondo D, Cordeiro ER, van Donselaar-van der Pant $\mathrm{KA}$, Bemelman FJ, et al. (2014) The 1-year decline in estimated glomerular filtration rate (eGFR) after radical nephrectomy in patients with renal masses and matched living kidney donors is the same. BJU Int 113: E49-E55.

10. Levey AS, Bosch JP, Lewis JB, Greene T, Rogers N, et al. (1999) A more accurate method to estimate glomerular filtration rate from serum creatinine: a new prediction equation. Modification of Diet in Renal Disease Study Group. Ann Intern Med 130: 461-470.

11. Levi A, Stevens PE, Bilous RW, Coresh J, de Francisco Angel LM, et al. (2013) Kidney Disease: Improving Global Outcomes (KDIGO) CKD Work Group KDIGO 2012 clinical practice guideline for the evaluation and management of chronic kidney disease. Kidney Int Suppl 3: 1-150.

12. Chung JS, Son NH, Byun SS, Lee SE, Hong SK, et al. (2014) Trends in renal function after radical nephrectomy: a multicentre analysis. BJU Int 113: 408-415.

13. Yokoyama M, Fujii $\mathrm{Y}$, Takeshita $\mathrm{H}$, Kawamura N, Nakayama T, et al. (2014) Renal function after radical nephrectomy: development and validation of predictive models in Japanese patients. Int J Urol 21: 238-242. 
14. Dols LF, Kok NF, Roodnat JI, Tran TC, Terkivatan T, et al. (2011) Living kidney donors: impact of age on long-term safety. Am J Transplant 11: 737-742.

15. Jeon HG, Jeong IG, Lee JW, Lee SE, Lee E (2009) Prognostic factors for chronic kidney disease after curative surgery in patients with small renal tumors. Urology 74: 1064-1068.

16. Bello RC, Bello VA, Rosa TT, Junqueira LF Jr, Freitas E, et al. (2015) Male Gender and Body Mass Index are Associated with Hypertension and Reduced Kidney Function 5 or More Years after Living Kidney Donation. Transplant Proc 47: 2816-2821.
17. Mjøen G, Oyen O, Midtvedt K, Dahle DO, Norby G, et al. (2011) Age, gender, and body mass index are associated with renal function after kidney donation. Clin Transplant 25: E579-E583.

18. Timsit MO, Nguyen KN, Rouach Y, Elie C, Loupy A, et al. (2012) Kidney function following nephrectomy: similitude and discrepancies between kidney cancer and living donation. Urol Oncol 30: 482-486.

19. Ohno Y, Nakashima J, Ohori M, Hashimoto T, Iseki R, et al. (2011) Impact of tumor size on renal function and prediction of renal insufficiency after radical nephrectomy in patients with renal cell carcinoma. J Urol 186: 1242-1246. 